\title{
BIOLOGICAL INTERACTION OF STRESS AND IRRITABLE BOWEL SYNDROME
}

\author{
Niraj Khatri Sapkota, Dev Kumar Shah, Md. Nazrul Islam \\ Department of Physiology, Chitwan Medical College, Bharatpur, Nepal
}

Correspondence to: Md. Nazrul Islam (drnazrul.16@gmail.com)

\author{
DOI: 10.5455/ijmsph.2014.150920141 Received Date: 21.07.2014 Accepted Date: 15.09.2014
}

\begin{abstract}
A variety of stressors play a role in the development of irritable bowel syndrome. Irritable bowel syndrome is a biopsychosocial disorder that results from dysregulation of central or enteric nervous system function. The physiological effects of psychological and physical stressors on gut function and brain-gut interactions are mediated by outputs of the emotional motor system in terms of autonomic, neuroendocrine, attentional, and pain modulatory responses. Certain investigational studies reported to date indicate that the activation of CRF1 pathways may result in a combination of effects that are key features of symptoms in some irritable bowel syndrome patients. These include stimulation of colonic motility, defecation or watery diarrhea, gut hypersensitivity that increases the perception of stimuli within the bowel, focused attention (hypervigilance) toward the gut sensations, and mast cell activation. Blocking the CRF1 receptors may alleviate all these effects. Stress thus can be included in an integrative model explaining the pathophysiology of functional bowel disorder. Advances in the understanding of the relationship between stress and visceral perception may constitute a basis for a therapeutic approach of functional bowel disorders targeted on the central nervous system.

Key Words: Stress; GI Activity; Corticotropin Releasing Factor; Irritable Bowel Syndrome
\end{abstract}

\section{Introduction}

Irritable bowel syndrome (IBS) is a highly prevalent functional gastro-intestinal disorder affecting predominantly the colon which is mainly characterized by abdominal pain and discomfort in association with altered bowel habits in the absence of any structural abnormalities.[1] Various stressors in the form of early life trauma, sexual abuse, maternal neglect, fear conditioning, life-threatening events, and enteric infections have an important role in the etiology of IBS. [25] Acute physical and psychological stress alters gutspecific efferent autonomic innervations. However, increased visceral sensation in patients with IBS suggests the involvement of a different regulatory mechanism, either central or peripheral.[6]

Stress activates different brain regions to coordinate the behavioral and physical changes which allow the organism to adapt. It triggers two main pathways: pituitary-adrenal axis and autonomic nervous system. Pituitary-adrenal axis acts to increase circulating hormones (glucocorticoids - particularly cortisol) which regulates the body's response to stress while later regulates different involuntary bodily functions including the bowel activity. Both of these pathways directly or indirectly affect enteric nervous system and collectively forms brain-gut axis.[7-9]

Stress induced somatic hypoalgesia mediated by descending pain inhibitory pathways involving opioidergic, glutaminergic, and serotonergic systems can be accompanied by a stress induced visceral hyperalgesia indirectly mediated by sympathetic and/or parasympathetic nerves stimulating the release of chemicals from mast and enterochromaffin like (ECL) cells within the gut wall which sensitizes the visceral afferent terminals. The net effect of simultaneous activation of both pain facilitatory and inhibitory systems in response to stress is determined by the relative contribution of these opposing influences.[10-13] Alterations in these endogenous stress activated pain modulation systems may play an important role in several functional visceral or somatic syndromes characterized by chronic discomfort and pain, features of IBS. [14]

\section{Stress and Gut Function}

Various stressors have revealed inhibition of gastric emptying and stimulation of colonic motor function. Activation of brain corticotropin releasing factor (CRF) receptors mediates stress-related inhibition of upper GI and stimulation of lower GI motor function through interaction with different CRF receptor subtypes.[15-17] Several reports consistently established that CRF injected into the cerebrospinal fluid (CSF) acts in the brain to inhibit gastric emptying of a solid or liquid meal and contractility in rats and dogs.[18,19] The paraventricular nucleus (PVN) of the hypothalamus and dorsal vagal complex (DVC) are responsive sites for CRFinduced delayed gastric emptying and inhibition of 
central vagal stimulation of gastric motility in rats, respectively. [19] The central mechanism for activation of autonomic effect for the gut function also includes amygdala which is centre to emotional system related to the stress. ${ }^{[20]}$ The amygdala is an important structure for regulating anxiety with the central nucleus of the amygdala facilitating the activation of the hypothalamicpituitary-adrenal axis and the autonomic nervous system in response to stress. Moreover, chronic stress enhances function of the mineralocorticoid and glucocorticoid receptor-mediated mechanisms within the amygdala in the regulation of anxiety and nociceptive behaviors that are characteristic features of IBS.[21]

Though there is a well-defined relationship between the immune and neuroendocrine systems through which immune signals activate the hypothalamic-pituitaryadrenal axis, central CRF-induced delayed gastric emptying is independent from the activation of pituitaryadrenal hormone release. ${ }^{[22]}$ It is most likely related to the alterations of autonomic nervous system activity, in which the decrease in gastric vagal outflow plays a major role.[19]

\section{CRF Receptors and Gut Activity}

One of the most important discoveries in the last decade in identifying the substances related to stress response is a family of peptides named corticotropin-releasing factor (CRF): urocortin 1, urocortin 2, and urocortin 3. CRF plays a crucial role in the stress-related stimulation of the hypothalamo-pituitary-adrenal axis and, in association with urocortins, acts as a neuromodulator to coordinate the behavioural, autonomic, and visceral efferent limbs of the stress response.[23-26] These peptides act as messengers and interact with CRF receptors $\left(\mathrm{CRF}_{1}\right.$ and $\left.\mathrm{CRF}_{2}\right)$ located, among other sites, both in the gut and brain regions linked with digestive function, emotional behaviour, and autonomic nervous system activity.[16] It is increasingly recognized that $\mathrm{CRF}_{1}$ receptors activated by CRF and urocortin 1 in brain stress network increase the anxiety- like behaviour along with changes in endocrine function and in gut these peptides change the colon functions, such as muscle contractions or motility, secretion and pain sensitivity leading to abdominal pain and development of watery stool or diarrhea.[17-19] In particular, CRF increases mucus and water secretion into the colon from cells lining the colon wall, and activates the enteric nervous system. $[17]$

It is documented that peripheral injection of CRF or urocortin stimulates colonic transit, motility through Fos gene expression in myenteric neurons, and defecation as a result of $\mathrm{CRF}_{1}$ receptors activation, whereas it decreases ileal contractility via $\mathrm{CRF}_{2}$ receptors. Some pre-clinical studies have shown that CRF administration into brain mimics acute stress-induced colonic responses and enhances colorectal distension-induced visceral pain in rats through $\mathrm{CRF}_{1}$ receptors. ${ }^{[27]}$ Similarly, peripheral $\mathrm{CRF}$ reduced the pain threshold to colonic distension and increased colonic motility in humans and rodents. These observations imitate the manifestations of IBS, characterized by abdominal bloating/discomfort and altered bowel habits.[7,19]

CRF also stimulates mast cells to release substances that play a role in increasing permeability, bacterial uptake from inside the colon to the colonic tissue, and pain response. Similarly, when given CRF, muscle contractions in the colon and pain increases in IBS patients compared to healthy individuals. ${ }^{[17]}$ Decreased postoperative pain tolerance thresholds were found in patients with increased anxiety. Other compelling animal studies have shown that painful stimulation of the colon activates brain nerve cells through $\mathrm{CRF} / \mathrm{CRF}_{1}$ mechanisms associated with the development of increased vigilance and anxiousness. Therefore, it is conceivable that the increased sensitivity to abdominal pain in IBS patients may cause, in turn, a more pronounced, sustained, and/or frequent activation of $\mathrm{CRF} / \mathrm{CRF}_{1}$ pathways.[22] $\mathrm{CRF}_{1}$ antagonist abolished or reduced emotional distress, colonic motility, mucus secretion, mast cell activation, diarrhea, and pain brought on by CRF administration or stress. This also gives evidence supporting the role of $\mathrm{CRF}$ pathways in the gut response to stress in IBS patients.[2]

Indirect pharmacological evidence suggests that intracisternal CRF-induced inhibition of gastric emptying involves interaction with CRF-R2 in rats.[17,18] Astressin (CRF receptor antagonists) injected into the CSF or the PVN at doses preventing gastric response to centrally injected CRF, block the delayed gastric emptying induced by various forms of stress.[19] Additionally, intraperitoneal administration of $\mathrm{CRF}$ induces colonic mast cells degranulation via both $\mathrm{CRF}_{1}$ and $\mathrm{CRF}_{2}$ receptors and increases ions secretion and mucosal permeability to macromolecules, which can in turn promote intestinal inflammation and alter visceral sensitivity.[28] CRF-induced alterations of colonic and ileal functions mimic effects which are observed after stress exposure, and CRF receptor antagonists given 
peripherally prevent stress-induced GI dysfunction. Furthermore, CRF peptides can reproduce secretomotor and mucosal alterations in vitro. ${ }^{[29,30]}$ In addition to the brain, a role for peripheral CRF signaling in mediating stress-induced effects on gastrointestinal sensorimotor, mucosal and immune functions, may be components of underlying mechanisms involved in stress-related impact on irritable bowel syndrome.[1]

\section{Serotonin and IBS}

Serotonin (5-hydroxtryptamine [5-HT]), which is produced mainly by and stored in enterochromaffin like cells in the GI tract, is vital to normal gut function such as initiation and maintenance of peristalsis, secretion in the GI tract, and modulation of pain sensation. ${ }^{[31,32]}$ Recent research has uncovered a potential role for abnormal serotonin expression and/or signalling in IBS and other GI disorders. ${ }^{[3]}$ The potential effect of sex hormones such as estrogen and progesterone on serotonin remains to be elucidated. A recent study has shown that estrogen and progesterone influence the level of 5-HT type 3 (5HT3) receptor mRNA. ${ }^{[34]}$ In ovariectomized rats, lower levels of prostaglandin and progesterone resulted in significantly higher amounts of 5-HT3 receptor mRNA. When ovariectomized animals were treated with estradiol and progesterone, 5-HT3 receptor transcription levels returned to normal. Additional studies highlight the importance of serotonin reuptake transporter in IBS as polymorphisms in this gene resulted in a differential response to alosetron, a 5-HT3 receptor antagonist that is used to treat diarrhea-predominant IBS. $[35,36]$ Collectively, these results suggest that 5-HT3 receptor activity, which is a target of pharmacologic intervention in patients with diarrhea-predominant IBS, is regulated by female sex hormones. However, the importance of serotonin and its receptors, as well as serotonin polymorphisms, in predicting response to treatment remains an area of interest.

\section{Gender, Stress and IBS}

In general, more number of women complains of IBS than men. Though the reasons for these gender difference remains elusive, it is explained on behalf of difference in colonic transit time, visceral sensitivity, CNS processing and effect of estrogen and progesterone on gut function, psychological characteristics including somatization, depression, anxiety as well as history of sexual abuse. ${ }^{[37]}$ A study revealed that the colonic transit time is less in female and lower sympathetic tone. ${ }^{[38]}$
Female respond to stress by building attachment and care giving process referred as "tend and befriend" phenomenon mediated by oxytocin and endogenous opioids. This behavioural response may be linked to physiologic response such as down regulation of sympathetic nervous system and HPA axis. On the other hand, male respond with aggressive prototypic fight or flight response, thought to be due to androgen and stress arousal.[39,40]

Various observations have shown that sex hormone in women has influential role in IBS with report of looser stools, increased bowel symptoms, increased rectal sensitivity during and before menses. GI symptoms increases and intestinal transit decrease during pregnancy. ${ }^{[41-43]}$ Furthermore, study found that stressinduced visceral hypersensitivity in female rats is estrogen-dependent and mediated through neurokinin (NK1) receptor activation in the colon. ${ }^{[44,45]}$ Estrogen has direct effect on GI tract calcium dependent potassium channel affecting contractility. In addition, activation of the hypothalamic-pituitary-adrenal (HPA) axis enhances increased activation of the amygdala..[46] Elevated levels of progesterone and/or estradiol on the amygdala heightened the responsiveness to colorectal distension and thus disproportionately affected by IBS with menstrual cycle.[47]

Ovariectomy significantly decreases the magnitude of the viscero-motor reflex and L6-S1 dorsal horn neuronal activity in response to colorectal distension. The estrogen modulates the spinal cord processing and reflex responses to innocuous and noxious colorectal stimuli in female rats and may contribute to alteration in sensory processing associated with irritable bowel syndrome. ${ }^{[36]}$

\section{Conclusion}

In summary, these investigational studies reported to date indicate that the activation of $\mathrm{CRF}_{1}$ pathways may result in a combination of effects that are key features of symptoms in some IBS patients. These include stimulation of colonic motility, defecation/watery diarrhea, gut hypersensitivity that increases the perception of stimuli within the bowel (e.g., food, gas, motor contractions), focused attention (hypervigilance) toward gut sensations, and mast cell activation. Blocking the $\mathrm{CRF}_{1}$ receptors may alleviate all these effects. Thus, the emerging conceptual framework supports that sustained activation of the $\mathrm{CRF}_{1}$ system at sites in the brain and/or in the gut may be one component 
underlying IBS symptoms. Targeting these mechanisms by drugs that block the action of CRF on selected $\mathrm{CRF}_{1}$ receptor sites might be a treatment approach to reduce IBS symptoms more effectively.

\section{References}

1. Crowell MD, Shetzline MA, Moses PL, Mawe GM, Talley NJ. Enterochromaffin cells and 5-HT signaling in the pathophysiology of disorders of gastrointestinal function. Curr Opin Investig Drugs 2004; 5(1): 55-60.

2. Rivest S. Molecular mechanisms and neural pathways mediating the influence of interleukin-1 on the activity of neuroendocrine CRF motoneurons in the rat. Int J Dev Neurosci 1995; 13:135-146.

3. Halpert A, Drossman D. Biopsychosocial issues in irritable bowel syndrome. J Clin Gastroenterol 2005; 39: 665-669.

4. Mayer EA, Naliboff BD, Chang L, Coutinho SV. Stress and the gastrointestinal tract. V. Stress and irritable bowel syndrome. Am J Physiol (Gastrointest Liver Physiol) 2001; 280: G519-G524.

5. Mönnikes H, Tebbe JJ, Hildebrandt M, Arck P, Osmanoglou E, Rose $\mathrm{M}$, et al. Role of stress in functional gastrointestinal disorders. Evidence for stress-induced alterations in gastrointestinal motility and sensitivity. Dig Dis 2001; 19: 201-211.

6. Murray CD, Flynn J, Ratcliffe L, Jacyna MR, Kamm MA. Emmanuel AV. Effect of acute physical and psychological stress on gut autonomic innervations in irritable bowel syndrome. Gastroenterology 2004; 127(6): 695-703.

7. Johnson EO, Kamilaris TC, Chrousos GP, Gold PW. Mechanisms of stress: a dynamic overview of hormonal and behavioral homeostasis. Neurosci Biobehav Rev 1992; 16(2): 115-130.

8. Tsigos C, Chrousos GP. Physiology of the hypothalamic-pituitaryadrenal axis in health and dysregulation in psychiatric and autoimmune disorders. Endocrinol Metab Clin 1994; 23(3): 451 . 466.

9. Konturek PC, Brzozowski T, Konturek SJ. Stress and the gut: pathophysiology, clinical consequences, diagnostic approach and treatment options. J Physiol Pharmacol 2011; 62(6): 591-599.

10. Harris M, Feinmann C, Mason MK. Edi. Oral manifestations of systemic disease. Philadelphia: WB Saunders, 1990.

11. Delvaux MM. Stress and visceral perception. Can J Gastroenterol 1999; 13: 32A-36A.

12. Coutinho SV, Miller JC, Plotsky PM. Effect of perinatal stress on responses to colorectal distension in adult rats. Soc Neurosci 1999; 25: 687.

13. Wei F, Dubner R, Ren K. Nucleus reticularis gigantocellularis and nucleus raphe magnus in the brain stem exert opposite effects on behavioral hyperalgesia and spinal Fos protein expression after peripheral inflammation. Pain 1999; 80: 127-141.

14. Gue M, Del Rio-Lacheze C, Eutamene H, Théodorou V, Fioramonti J, Buéno L. Stress-induced hypersensitivity to rectal distension in rats: role of CRF and mast cells. Neurogastroenterol Motil 1997; 9(4): 271-279.

15. Taché Y, Martinez V, Wang L Million M. CRF1 receptor signaling pathways are involved in stress-related alterations of colonic function and viscerosensitivity: implications for irritable bowel syndrome. Br J Pharmacol 2004; 141(8): 1321-1330.

16. Taché Y, Martinez V, Million M, Maillot C. Role of corticotropin releasing factor receptor subtype 1 in stress-related functional colonic alterations: implications in irritable bowel syndrome. Eur J Surg Suppl 2002; 587:16-22.

17. Martinez V, Taché Y. CRF1 receptors as a therapeutic target for irritable bowel syndrome. Curr Pharm Des 2006; 12(31): 40714088.

18. Göran Hampf. Hypersensitivity due to stress. Anesth Prog 1989; 36(6): 265-267.

19. Larauche M, Kiank C, Tache Y. Corticotropin releasing factor signaling in colon and ileum: regulation by stress and pathophysiological implications. J Physiol Pharmacol 2009; 60 (7): 33-46.

20. Henke PG, Ray A, Sullivan RM. The amygdala. Emotions and gut functions. Dig Dis Sci 1991; 36(11): 1633-43.
21. Brent M, Beverley G, Van M. Role of anxiety in the pathophysiology of irritable bowel syndrome: Importance of the amygdala. Neurosci 2009; 3: 47.

22. Martínez $\mathrm{V}$, Taché Y. Role of CRF receptor 1 in central CRFinduced stimulation of colonic propulsion in rats. Brain Res 2001; 893: 29-35.

23. Herman J, Pokkunuri V, Braham L, Pimentel M. Gender distribution in irritable bowel syndrome is proportional to the severity of constipation relative to diarrhea. Gend Med 2010; $7(3): 240-246$

24. Bale TL, Vale WW. CRF and CRF receptors: role in stress responsivity and other behaviors. Annu Rev Pharmacol Toxicol 2004; 44: 525-557.

25. Stengel A, Tache Y. Neuroendocrine control of the gut during stress: corticotropin-releasing factor signaling pathways in the spotlight. Annu Rev Physiol 2009; 71: 219-240.

26. Tache Y, Kiank C, Stengel A. A role for corticotropin-releasing factor in functional gastrointestinal disorders. Curr Gastroenterol Rep 2009; 11: 270-277.

27. Yvette $T$, Vicente $M$, Mulugeta $M$, Lixin W. Stress-related alterations of gut motor function: role of brain corticotropinreleasing factor receptors. Am J Physiol (Gastrointestinal and Liver) 2001; 280: G173-G177.

28. Binder EB, Nemeroff CB. The CRF system, stress, depression and anxiety-insights from human genetic studies. Mol Psychiatry 2010; 15(6): 574-588.

29. Larauche M, Kiank C, Tache Y. Corticotropin releasing factor signaling in colon and ileum: regulation by stress and pathophysiological implications. J Physiol Pharmacol 2009; 60 (suppl 7): 33-46.

30. Drossman DA. The functional gastrointestinal disorders and the Rome III process. Gastroenterol 2006; 130: 1377-1390.

31. Crowell MD. The role of serotonin in the pathophysiology of irritable bowel syndrome. Am J Manag Care 2001; 7(suppl 8): S252-S260.

32. Coates MD, Mahoney CR, Linden DR, Sampson JE, Chen J, Blaszyk $\mathrm{H}$, et al. Molecular defects in mucosal serotonin content and decreased serotonin reuptake transporter in ulcerative colitis and irritable bowel syndrome. Gastroenterol 2004; 126(7): 16571664.

33. Li TJ, Yu BP, Dong WG, Luo HS, Xu L, Li MQ. Ovarian hormone modulates 5-hydroxytryptamine 3 receptors mRNA expression in rat colon with restraint stress-induced bowel dysfunction. World J Gastroenterol 2004; 10(18): 2723-2726.

34. Camilleri M, Atanasova E, Carlson PJ, Ahmad U, Kim HJ, Viramontes BE, et al. Serotonin transporter polymorphism pharmacogenetics in diarrhea-predominant irritable bowel syndrome. Gastroenterol 2002; 123(2): 425-432.

35. Scherl E, Frissor CL. Irritable bowel syndrome genophenomics: correlation of serotonin-transporter polymorphisms and alosetron response. Pharmacogenomics 2002; J 3: 64-66.

36. Yaping Ji, Anne ZM, Richard JT. Estrogen modulates the visceromotor reflex and responses of spinal dorsal horn neurons to colorectal stimulation in the rat. J Neuroscience 2003; 23(9): 3908-3915.

37. Mulak A, Bonaz B. Irritable bowel syndrome: a model of the braingut interactions. Med Sci Monit 2004; 10: 52-60.

38. Motzer SA, Hertig V. Stress, stress response, and health. Nurs Clin North Am 2004; 39(1): 1-17.

39. Chang L, Heitkemper MM. Gender differences in irritable bowel syndrome. Gastroenterol 2002; 123(5): 1686-1701.

40. Taylor SE, Klein LC, Lewis BP, Gruenewald TL, Gurung RA, Updegraff JA. Biobehavioral responses to stress in females: tendand-befriend, not fight-or-flight. Psychol Rev 2000; 107(3): 411429.

41. Hansen MB. Neurohumoral control of gastrointestinal motility. Physiol Res 2003; 52: 1-30.

42. Houghton LA, Lea R, Jackson N, Whorwell PJ. The menstrual cycle affects rectal sensitivity in patients with irritable bowel syndrome but not healthy volunteers. Gut 2002; 50(4): 471-474

43. Heitkemper MM, Jarrett M. Patterns of gastrointestinal and somatic symptoms across the menstrual cycle. Gastroenterol 1992; 102: 505-513. 
44. Whitehead WE, Cheskin LJ, Heller BR, Robinson JC, Crowell MD, Benjamin C, et al. Evidence for exacerbation of irritable bowel syndrome during menses. Gastroenterol 1990; 98: 1485-1489.

45. Bradesi S, Eutamene H, Fioramonti J, Bueno L. Acute restraint stress activates functional NK1 receptor in the colon of female rats: involvement of steroids. Gut 2002; 50: 349-354.

46. Gué M. Visceral hypersensitivity in response to rectal distension in female rats: Role of sexual hormones. In: Krammer HJ, Singer MV editor. Neurogastroenterology from the basics to the clinics. Kluwer, Dordrecht. pp. 758-762, 2000.

47. Jenny KG, Beverley G, Van M. Amygdala activation by corticosterone alters visceral and somatic pain in cycling female rats. Am J Physiol (Gastrointestinal and Liver Physiology) 2011; 300: G1080-G1085.

Cite this article as: Sapkota NK, Shah DK, Islam MN. Biological interaction of stress and irritable bowel syndrome. Int J Med Sci Public Health 2014;3:1182-1186.

Source of Support: Nil

Conflict of interest: None declared 